\title{
S-layer proteins from lactobacilli as vaccine delivery systems
}

\author{
Axel Hollmann ${ }^{1 *}$, Lucrecia Delfederico ${ }^{1}$, Anderson Miyoshi ${ }^{2}$, Edgardo \\ Anibal Disalvo $^{3}$, Graciela De Antoni4, Liliana Semorile ${ }^{1}$, Vasco Azevedo ${ }^{2}$ \\ ${ }^{1}$ Laboratorio de Microbiología Molecular, Departamento de Ciencia y Tecnología, Universidad Nacional \\ de Quilmes, Bernal, Argentina, ahollmann@gmail.com; ${ }^{2}$ Instituto de Ciências Biológicas, Universidade \\ Federal de Minas Gerais, Belo Horizonte, Brasil; ${ }^{3}$ Laboratorio de Fisicoquímica de Membranas Lipídicas \\ y Liposomas, Cátedra de Química General e Inorgánica, Facultad de Farmacia y Bioquímica, \\ Universidad de Buenos Aires, Buenos Aires, Argentina; ${ }^{4}$ Centro de Investigación y Desarrollo en \\ Criotecnología de Alimentos (CIDCA), Facultad de Ciencias Exactas, Universidad Nacional de La Plata, \\ La Plata, Argentina.
}

\begin{abstract}
The S-layer, crystalline arrays of proteinaceous subunits, seems to be a typical surface structure in several lactobacilli species. Due their self-assembly ability to recrystallize into isoporous monolayers in suspension, at liquid-surface interfaces, lipid structures and on solid supports, S-layers were demonstrated to possess a great potential for nanobiotechnological applications. Interest in lactobacilli S-layer has been reinforced by claimed and demonstrated probiotic properties for human and animal consumers. Several lactobacillar S-layer have been found to be involved in adherence to intestinal epithelial cells and to the mammalian extracellular matrix. Due to these observed adhesive properties, the possible therapeutic applications of lactobacillar S-layers have become increasingly of interest, e.g. as targeted antigen delivery vehicles to host tissues. In addition, S-layers may provide superior expression levels and surface density of antigens when compared to other bacterial antigen presentation systems. It has already been demonstrated that S-layer protein subunits can be modified to carry foreign epitopes as a uniform recombinant S-layer on the Lactobacillus cell surface. The adhesion and immunogenic functions of S-layer proteins, combined with the properties of Lactobacillus spp., could lead to new, safe, and stable liposomal particles for drug delivery.
\end{abstract}

Key Words: S-layer proteins, lactobacilli, oral delivery, liposomes, vaccine design

\section{INTRODUCTION}

Lactobacilli are Gram-positive, rod-shaped members of the lactic acid bacteria (LAB) group; they are characterized by the formation of lactic acid as the sole or main product of sugar fermentation. They are found where rich, carbohydrate-containing substances are available; hence $L A B$ occur in a wide variety of habitats such as the mucosal membranes of humans and animals (oral cavity, vagina and gastrointestinal tract), on plants, in manure and man-made habitats such as sewage and fermented or spoiled food [[1], 2]. The food and feed industry utilizes lactobacilli widely in different fermentative processes [[3]]. Due to their long history of use in food fermentation and in the food industry, and because of their lack of pathogenicity, lactobacilli are 'generally recognized as safe' (GRAS) organisms [[4]]. One of the outer surface components of cell envelopes of prokaryotic organisms, archaea and bacteria, are crystalline arrays of proteinaceous subunits, known as surface layers (S-layers), which usually are composed of single protein or glycoprotein species [[5], [6], [7]]. S-layer proteins have the capability to recrystallize into isoporous monolayers in suspension, at liquid-surface interfaces, lipid structures and on solid supports. Due their selfassembly ability, S-layers were demonstrated to possess a great potential for nanobiotechnological applications. The S-layer seems to be a typical surface structure in several lactobacilli species [[4]]. Interest in lactobacilli $\mathrm{S}$-layer has been reinforced by claimed and demonstrated probiotic properties for human and animal consumers [1, 8]. The aim of the present work is to organize the vast information concerning S-layer proteins, particularly S-layers from lactobacilli, spotlighting/underlining those aspects related to properties that make them attractive candidates for mucosal vaccine-delivery vehicles.

\section{S-layer proteins: Generalities 1.1 Location and ultrastructure}

When present, S-layers completely surround cells as the outermost component of their envelope, except for the organisms witch posses capsule like Bacillus anthracis, where the capsule is the external structure [[9]]. They have been described in most of the main branches of the Bacteria and Archaea domains [[9], [11], [12]]. In archaea, S-layer lattices often constitute the only cell wall component, and some of them are anchored by pillar-like domains to the plasma membrane [[13]]. In Gram-positive bacteria, the lattice assembles on the surface of the cell wall, which is composed mainly of peptidoglycan.

In Gram-negative bacteria, the S-layer is attached to the lipopolysaccharide (LPS) component of the outer membrane [[14]]. Some Gram-positive and Gram-negative bacteria can produce two superimposed S-layers; usually, each is composed of a different subunit species [[15]], Fig. (1). Molecular masses of S-layer proteins range from 25 to $220 \mathrm{kDa}$; within species, S-layer proteins may also vary in size, depending on strain and growth conditions 
[[16], [17]]. Most S-layers consist of a single protein or glycoprotein that polymerizes to form bidimensional paracrystalline structures. Only a few organisms, including Clostridium difficile and $B$. anthracis, have S-layer proteins with two types of subunits [[18], [19], [20]]. Electron microscopy of negative staining or freezeetched preparations, Fig. (2), are necessary to identify S-layers [[15]].

High-resolution studies on the mass distribution of lattices are generally made with negatively stained, frozen S-layer fragments, or with recrystallized S-layer lattices. Surface topography of S-layers can also be studied through atomic force microscopy (AFM), which is increasingly used to investigate the forces within or between single biomolecules [[21]]. The S-layer crystal lattice may have oblique (p1, p2), tetragonal (p4), or hexagonal (p3, p6) symmetry. Depending on the pattern, a morphological unit of the S-layer consists of one, two, three, four, or six protein subunits, Fig. (3). Center-to-center spacing of the morphological units can vary from 2.5 to 35.0 $\mathrm{nm}$; thus, the lattices can be quite porous, with pores occupying up to $\sim 70 \%$ of their surface. The pores within an S-layer are of identical size (usually in the 2-8 nm range) and shape. Frequently, two or more distinct classes of pores are present. A common feature of Slayers is their smooth outer surface and more corrugated inner surface. Most S-layer subunits are weakly acidic proteins, and thus showed a charge-neutral outer and a net-negative inner face at a neutral $\mathrm{pH}[[16]]$.

\subsection{Isolation and self- assembly}

Interactions between S-layer subunits, as well as between the S-layer and the supporting envelope, can be disrupted in a reversible manner by cation substitution or by a high concentration of chaotropic agents [[22], [14]]. This demonstrates that individual S-layer subunits interact with each other and with the supporting cell envelope components through noncovalent bonding. Isolated S-layer subunits frequently maintain the ability to recrystallize into regular arrays in suspension or on surfaces after removal of the isolation agent. These arrays obtained in vitro exhibit structural features that are often indistinguishable from those found surrounding the cells in vivo. Slayers differ considerably in their susceptibility to disruption into monomeric subunits.

They are normally isolated from purified cell wall fragments by the addition of hydrogenbond-breaking agents (urea or guanidine hydrochloride), detergents (at $\mathrm{pH}<4.0$ ) or by cation substitution (e.g. $\mathrm{Na}+$ or $\mathrm{Li}+$ replacing $\mathrm{Ca2+)}$ [[14]]. Intersubunit bonds are stronger than those that bind the lattice to the underlying envelope layer; this property is a basic requirement for continuous recrystallization of the lattice during cell growth [[15], [24]].

\subsection{Chemical characterization and primary structure}

Most S-layer proteins include little or no sulfurcontaining amino acids and have a high content of acidic and hydrophobic amino acids, lysine being the predominant basic amino acid [[4]]. They usually have an acidic isoelectric point, but there are a few exceptions, including S-layer proteins from lactobacilli and the archaea Methanococcus, which have high $\mathrm{pH}$ isoelectric points. A remarkable characteristic of many archaeal and some bacterial S-layers is their glycosylation. The glycan of Halobacterium S-glycoprotein consists of short, predominantly N-glycosidically-linked sulfonated heterosaccharides [[23]]. In contrast, glycans isolated from Bacillaceae S-layers are assemblies of identical, repeating units, with up to 150 monosaccharide residues, attached primarily by O-glycosidic linkages. These include novel linkage types, such as $\beta$ glucose $\rightarrow$ tyrosine, $\beta$-galactose $\rightarrow$ tyrosine and $\beta-\mathrm{N}$-galactosamine $\rightarrow$ threonine/serine $\quad[[25]]$. The genetic information for S-layer glycan biosynthesis is usually present in S-layer glycosylation (slg) gene clusters acting in concert with housekeeping genes [[26]]. Concerning an overall function of S-layer glycoproteins in non-pathogenic bacteria, it is conceivable that, by representing the outermost cell surface structure of a bacterium, they participate in diverse cell surface phenomena and, simultaneously, contribute to a high diversification potential of the bacterial cell surface, which may be advantageous in the competitive natural habitat [[26]] Carbohydrates may provide also local protection against proteases through steric hindrance and consequently contribute to the stability of S-layers [[27]]. Due to the lack of suitable tools for genetic manipulation of bacterial S-layer glycosylation pathways, progress in the elucidation of the glycan biosynthesis mechanism, was limited to in vitro testing of individual enzymes from these pathways [[28]] and to heterologous carbohydrate-engineering approaches in the past [[29]]. Recently Zarschler et al. [[30]] have reported a successful genetic manipulation of bacterial S-layer protein glycosylation in vivo with promising applications in nanobiotechnology [[30]]. No homology has been found among S-layer protein sequences from phylogenetically unrelated organisms, suggesting strong selective pressure against their maintenance (through proteases, phages and the immune system). The main exception to this rule is the finding of one or more copies of the S-layer homology (SLH) motif in the Slayer sequences of some Gram-positive bacteria and of the Thermus group [[31]]. Tandemly organized SLH motifs have also been identified in extracellular enzymes from Gram-positive bacteria [[32]]; in these enzymes, SLH motifs facilitate binding to peptidoglycan [[27], [33]]. S-layerpeptidoglycan associations are mainly 
mediated by specific contacts (SLH) domains either bind directly to the peptidoglycan [[34]] or to a pyruvylated carbohydrate that is covalently linked to the peptidoglycan [[25]].

\section{S-layer proteins from lactobacilli}

S-layers have been found on the cell surface of several Lactobacillus species of the $L$. delbrueckii, L. reuteri, L. brevis, L. buchneri and L. casei phylogenetic groups [[35], [1]], Fig (4). Lactobacillar S-layers have some common and distinctive features, such as a low content of cysteine and methionine, as well as a high content of hydrophobic and hydroxyl amino acids. Relatively small sizes ( 25 to $71 \mathrm{kDa}$ ) are characteristic of lactobacillar S-layer proteins [[4]]. These proteins also have an N-terminal secretion peptide (SP), as well as many other prokaryotic S-layer proteins [[12]]. Several members of the L. delbrueckii group possess two genes encoding surface proteins, one silent and one actively transcribed [[36], [37]] (Table 1). These bacteria may express alternative S-layer protein genes, probably to adapt to different stress factors, such as drastic changes in the environmental conditions. Generally, S-layer variation is a consequence of DNA rearrangements; however, variation of S-layer protein content in L. brevis ATCC 14869 occurs through a unique mechanism involving activation of transcription by a soluble factor, constituting response to changes in the environment [[17]]. Multiple genes coding for Slayer proteins is a feature that lactobacilli share with other bacteria, including Bacillus anthracis [[38]], Clostridium fetus [[39]] and Tannerella forsythia [[40]]. In S-layer proteins of lactobacilli, no SLH motifs have been detected but the attachment of the S-layer protein to the cell wall seems to involve also secondary cell wall polymers in several species [[27]]. The Slayer proteins from L. brevis and L. buchneri are reported to bind to a neutral polysaccharide moiety of the cell wall [[41], [42]]. Interaction studies performed with truncated rSIpA of $L$. brevis ATCC 8287 confirmed that $\mathrm{N}$-terminal region of S-layer protein is responsible to cell wall binding [[43]]. On the other hand, the location of the cell wall binding domain of the $L$. acidophilus ATCC 4356 SIpA and L. crispatus JCM 5810 CbsA has been determined to reside in the C-terminal one third of these proteins. Interactions between a positively charged Slayer protein region and negatively charged secondary cell wall polymers have been shown to mediate the cell wall binding in the case of SIpA of L. acidophilus ATCC 4356 [[44]] and CbsA of L. crispatus JCM 5810 [[45]]. It was shown that SIpA and CbsA bind to teichoic acids, and CbsA binds also to lipoteichoic acids purified from Staphylococcus aureus and Streptococcus faecalis, but not to the teichuronic acid/polysaccharide fraction of the cell wall of L. crispatus JCM 5810 [45].

\section{S-layer glycoproteins in lactobacilli}

Glycosylation represents the most common post-translational modification in S-layer proteins and it has been demonstrated in many archaeal and bacterial genera. Although most of S-layers from lactobacilli appear to be nonglycosylated [4] to date, glycan structures have only been found in L. buchneri [[46]], L. kefiri [[47], [48]] and L. helveticus [[49]]. For L. kefiri recently were described five molecules of glucose and five molecules of mannose [[47]] in a good correlation with previously reported from L. buchneri, which have six to eight molecules of glucose for each protein unit [[50]]. In both proteins, the glycan structures represent less than $10 \%$ of weight, in concordance with data reported for other Slayer proteins describing that the degree of glycosylation generally varies between $1 \%$ and $10 \% \quad(w / w)$ [[51]]. It was reported that glycosylation adds significantly to the potential functional spectrum of S-layer proteins [[51], [23]]. Mobili et al. [[48]] have been proposed that glycosylation on S-layer protein of $L$. kefiri could be related with the aggregation ability of these bacteria. Furthermore, the presence of glycosidic groups on this bacterium seems to be related with a higher affinity of these proteins with positively charged lipid membranes [[53]]. However, further studies should be made in order to clarify the specific relationship between glycosylation and affinity features of S-layer proteins from $L$. kefiri. Besides these effects, it has been reported that glycosylation contributes to protein antigenic properties [20], an interesting feature in the development of a vaccine carrier. Glycoengineering applications appears as a novel and interesting field of study that may include receptor mimics, vaccine design, or drug delivery using carbohydrate recognition [30]. Since the S-layer glycome is connected with a molecular self-assembly system, there is a strong link to the field of nanobiotechnology, because means for organizing materials, such as biologically functional glycans, at the nanometer level are prime candidates for the production of supramolecular structures and devices [[51]].

\subsection{S-layer proteins functions}

Synthesizing S-layer proteins is energy consuming and their productions are exquisitely regulated, suggesting that they each have a defined role [[9]]. However, no general function has been identified for S-layer proteins and many of the functions assigned are still hypothetical. Though they have been found in most of the phylogenetic branches of microorganisms, the function of S-layers is assumed specific for genera or groups of organisms in the same environment rather than common to all prokaryotes [[9]]. S-layers function as protective coatings, molecularsieves in the ultrafiltration range (constituting molecule and ion traps), promoters of cell adhesion and surface recognition, determiners of cell shape in archaea and some bacteria, 
and virulence factors in pathogenic microorganisms [[4]]. Little is known about the function of S-layer proteins in lactobacilli. They have been found to be involved in adherence to intestinal epithelial cells [[54], [55]] and to the mammalian extracellular matrix [[56], [37], [57]] (Table 2). L. crispatus JCM 5810 adheres efficiently to collagen and laminin, which are major components of the mammalian extracellular matrix (ECM); extracted S-layer protein from this species binds to collagen IV [[57]]. The N-terminal portion of the molecule is responsible for binding to host receptors [[45]]. This was also observed for S-layer proteins SIp A of L. brevis ATCC 8287 [[56]]. JakavaViljanen et al. found that S-layers of lactobacilli isolates from pig intestines and feces adhere to mammalian intestinal-epithelial-cell lines, intestinal and gastric mucus, and ECM components [[58]]. Treatment of $L$. kefiri and L. parakefiri cells with lithium chloride (LiCl) eliminate their hemagglutination properties [[22]]. Adhesive functions were also suggested for S-layer proteins from $L$. acidophilus M92 [[51]]. Adherence of probiotics to intestinal epithelial cells and temporary colonization of the gut are considered crucial for their beneficial health effects [[59], [60]]. Adhesive S-layers can inhibit adhesion of pathogenic bacteria, contributing to the probiotic effects of lactobacilli. Probiotic activity is generally a function of bacterial surface properties [[61], [62]]. Recently, based on analysis by surface plasmon resonance, SIpA of L. brevis ATCC 8287 was found to interact with fibronectin and laminin [[63]]. Good adhesion properties could play a role in the competitive exclusion of potentially harmful microbes by L. brevis ATCC 8287. Golowczyc et al. [[64]] showed that preincubation of salmonella cells with S-layer proteins from $L$. kefiri leads to changes in the surface properties of this bacterium, so that they are no longer able to invade cultured human enterocytes. That S-layer protein from $L$. kefiri is also responsible of co-aggregation with the yeast Sacharomyces lipolitica. These results and the capacity of purified S-layer proteins of $L$. kefiri to haemagglutinate strongly suggest that a lectin-like activity of bacterial surface proteins (S-layer) mediates the aggregation with yeast cells [[65]]. The S-layer proteins of L. crispatus strain ZJ001 is responsible for competitive exclusion against Escherichia coli 0157:H7 and Salmonella typhimurium [[66]]. In addition, S-layer protein extracts from $L$. helveticus R0052 can inhibit enterohaemorrhagic $E$. coli adhesion to host epithelial cells [[67]]. Zhang et al. [[68]] have shown that $L$. paracasei subp. paracasei, $L$. rhamnosus, and $L$. casei strains isolated from natural dairy products are capable of exerting a significant degree of inhibition of Shigella sonnei adhesion to HT-29 cells, and their Slayer proteins contributed to this inhibition activity. For S-layer proteín of $L$. acidophilus ATCC 4365 was described a true murein hydrolase activity associated with this S-layer, with lytic activity toward the cell walls of several bacteria [[69]]. A role of murein hydrolase for an S-layer protein had previously been described only for Bacillus anthracis [[69]]. Furthermore was also probed that, in combination with nisin, the S-layer from $L$. acidophilus acts synergistically to inhibit the growth of pathogenic Salmonella enteric, Staphylococcus aureus and Bacillus cereus [[70]]. Recently, the obtention of knockout for S-layer protein SIpA in L. acidophilus allowed a better understood of S-layer proteins; the slpA mutant grew as small curved bacilli, reinforced the idea of S-layer proteins are involved in cell shape determination [[54]]. The slpA mutant also lost in $84 \%$ its adhesive properties to Caco- 2 cells. Removal or alteration of a surface layer can have many dramatic cellular effects, not the least of which may be on surface charge, architecture, and the presence or conformation of various surface proteins involved in attachment [[54]]. Other functions for S-layers have also been identified. The Slayer protein of $L$. helveticus CNRZ 892 functions as a receptor for a phage [[71]]. Slayers have been proposed to have a role in cell shape determination and cell wall stabilization [[15]]. Extraction of S-layer proteins reduced the viability of $L$. acidophilus in simulated gastric and small intestinal juice, suggesting a protective role for the S-layer [[71]].

Taking into account all above-mentioned Slayer functions that reinforce the probiotic properties of lactobacilli, characterization of different lactobacillar S-layer proteins is key to the selection of useful strains.

4. S-layer proteins in vaccine technology
4.1 S-layer proteins as immunogenic agents
One of the most relevant areas of research in
nanobiotechnology is the technological
utilization of self-assembly systems [[72]].
Individual S-layer subunits contain all the
information required for assembly into a regular
array; isolated subunits can assemble into
organized structures, resembling those
observed on intact cells [[15]]. The natural
assembly of S-layers into large regular arrays
endows them with immune-stimulating and
intrinsic-adjuvant properties [[51], [73]]. The
location of the foreign antigen within the S-layer
protein may not be crucial for vaccine
production, as long as sufficient amounts of
expression are obtained and sheet-like
structures are formed. The potential of S-layers
as antigen carriers for vaccine preparations has
been demonstrated [[74], [75]].
Polysaccharides and proteins can be
chemically linked to S-layers; the use of such
conjugates induces immune responses in
animal models. Insertion of foreign proteins into
S-layers by genetic manipulation avoids the
need for toxic chemicals and ensures the
presence of these proteins in every S-layer
protein subunit [[76]]. T-cell-mediated immunity
can be induced in BALB/c mice by
4.1 S-layer proteins as immunogenic agents One of the most relevant areas of research in nanobiotechnology is the technologica information required for assembly into a regular array; isolated subunits can assemble into endows them with immune-stimulating and intrinsic-adjuvant properties [[51], [73]]. The production, as long as sufficient amounts of expression are obtained and sheet-like structures are formed. The potential of S-layers Polysaccharides and proteins can be chemically linked to S-layers; the use of such S-layers by genetic manipulation avoids the need for toxic chemicals and ensures the protein subunit [[76]]. T-cell-mediated immunity can be induced in BALB/c mice by 
oligosaccharide haptens immobilized on crystalline S-layers [[72]]. The use of S-layer proteins as a carrier for birch pollen allergen diverts the response to vaccination from an allergic $\mathrm{TH} 2$-mediated reaction towards a more favorable $\mathrm{TH} / \mathrm{TH} 1$ reaction [[75]]. High levels of recombinant S-layer protein expression have been achieved with bacterial ghosts. A combination of recombinant S-layers and bacterial ghosts is one of the potential applications of ghost-platform technology. Sheet-like S-layer structures, harboring the desired antigen, are entrapped in the cytoplasm of the ghost during the lysis process [[77]]. The sealed periplasm of a ghost constitutes another compartment that can be filled with soluble proteins [[77]] or recombinant S-layers [[76]]. Whether it is advantageous to present the antigen in different compartments remains to be elucidated [[76]]. Immunization with purified Omp26 S-layer protein from Bacillus thuringiensis was found to be suitable for cell-surface display [[78]]. This approach opens the possibility of generating live, heatstable, oral veterinary vaccines against infectious diseases of fowl, using the Bacillus thuringiensis S-layer protein CTC surfacedisplay system [[79]]. Recently Khang et al. [[80]] showed that a mixture of the L. brevis Slayer fusion proteins and the specific antibodies against coronavirus, rotavirus, Escherichia coli, and Salmonella typhimurium to newborn Hanwoo calves twice a day resulted in successful protection from neonatal calf diarrhea syndrome for about three weeks. This is the first report to treat neonatal calf diarrhea syndrome effectively using the recombinant Lactobacillus S-layer proteins. Thus, the results open promising applications of the bacterial Slayer proteins in the animal industry as well as in the bioindustry for protein immobilization [[80]]. Konstantinov et al. [[81]] recently established that the SIpA-dominant $L$. acidophilus NCFM interacts with a major receptor on dendritic cells and regulates its immune functions. It suggests that this probiotic bacterium could directly or indirectly interfere with pathogen-induced effects on the host immune system. These data establish a working hypothesis on the mode of action of probiotic cultures that will guide further investigations into the mechanisms by which these bacteria impact Gl states. The work also suggests that the potential switch between $S$ layer proteins SIpA and SIpB might lead to differential immune responses impacting the gut immune homeostasis. Therefore, further studies need to address at what extent the ratio of SIpA to SIpB present on the surface of different intestinal LAB [[81]].

\subsection{Lactobacillar S-layer proteins and} vaccine delivery

Lactobacilli have several properties that make them attractive candidates for mucosal vaccine-delivery vehicles. The intrinsic properties of lactobacilli to modulate the immune system make them attractive for health applications, in particular for the in vivo production and delivery of biologically active molecules [[82]]. Modulation of the immune system can occur through the intrinsic adjuvanticity and cytokine-inducing properties of lactobacilli. Recently, there has been increased interest in the possibility of genetically manipulating lactobacilli, both for probiotic use [[83]] and for delivering mucosal vaccines [[84]]. Various cellular locations have been tested for antigen production with lactococci and lactobacilli [[85], [86]]. If Lactobacillus species could be engineered in such a way that each S-layer protein monomer was fused to a foreign antigen, the concentration of antigen at the bacterial surface would be very high. Identification and characterization of adherence factors has therefore become a topic of special interest [[87]]. S-layer proteins can account for $10-12 \%$ of total cell proteins. This high level of expression facilitates large-scale production of target proteins. More importantly, since S-layer proteins are expressed on the cell surface and are either secreted or can be easily released from the cell surface, recovery and purification of S-layer fusion proteins is relatively simple [[88]]. Smit et al. [[44]] demonstrated that it is possible to surface-expose epitopes as part of the S-layer of $L$. acidophilus. Efficient transcription of S-layer protein genes is required, since synthesis of up to $5 \times 105 \mathrm{~S}$ layer protein subunits has been calculated to be required for complete formation of an Slayer on an average-sized cell [[89]]. Studies in the activities of the two promoters of SlpA from $L$. brevis, by measuring reporter enzyme activities and transcript amounts in recombinant strains, showed the high expression levels of both slpA and the reporter genes. Furthermore, recombinant $L$. brevis strains remain on a substantially high level under conditions encountered in the gastrointestinal tract, by addition of bile or pancreatic extract in the growth medium, or after a change the carbon source. These findings encourage the research aiming at the use of $L$. brevis ATCC 8287 in live oral vaccines with its S-layer protein as an antigen carrier [[90]]. Similar results were found for sipA gene of $L$. acidophilus ATCC 4356, where slpA gene expression increased in the salt bile stress conditions [[91]]. Furthermore, in S-layer proteins of L. brevis ATCC 8287 it was demonstrated that self-assembly domain comprises residues 179-435 in mature protein, since truncated proteins encompassing this region were able to form a periodic structure indistinguishable from that formed by full length SIpA. The mapping of surface exposed residues in the self-assembly domain of SIpA is currently in progress and is a potential tool for mucosal immunization, and further studies concerning vaccine development [92]. Small epitopes can be surface-displayed as part of the S-layer proteins of lactobacilli [[92], [44]]. 
An intact S-layer without any changes in crystalline structure can be formed even if there is a heterologous epitope in every S-layer subunit [[92]]. A poliovirus VP1 epitope and a cMyc epitope from the human c-myc protooncogene have been successfully surface displayed in L. brevis SIpA protein [[92], [44]]. Recombinant $L$. brevis that displayed the c-Myc epitope in all of the S-layer protein subunits, without any effect on S-layer lattice structure, was obtained because of successful gene replacement [[92]]. Surface display in S-layers would thus be a very efficient and safe means to present antigens to the mucosal-associated lymphoreticular tissue [[92]].

Recently was showed that both $\operatorname{sipA}$ and $\operatorname{sipB}$ S-layer genes of L. crispatus ZJ001 expressed in $E$. coli with the addition of His tags, were adhesive to HeLa cells, although different in the structure of protein polymers. Therefore, the authors suggest that it is possible to explore the strain L. crispatus ZJ001 as a mucosal vaccine delivery vector, by engineering heterologous protein genes into slpA, because of the expression pattern and high cell binding ability of SIpA [[93]].

\subsection{Liposomes stabilized by S-layer proteins as vaccine carriers}

Liposome-antigen and liposome-DNA vaccines have frequently been tested using systemic routes of administration; various new products based on this technology are presently in use or in clinical development [[94]]. Biodegradability and low permeability to small hydrophilic molecules make liposomes excellent reservoirs for drug loading/release [[95]]. Development of effective delivery systems for the presentation of antigens to mucosal surfaces is critical to the success of vaccines [[96]]. Particulate antigens are more effective than soluble antigens for the induction of systemic and mucosal immunity, possibly because of more efficient endocytosis of particulate antigens by mucosal-associated lymphoid tissue (MALT) [[97]]. Liposomes are considered effective immunological adjuvants and have potential for intranasal and oral delivery of protein antigens [[98]]. However, delivery of pharmaceuticals via an oral route, particularly biotechnology products such as proteins, peptides, genes, oligonucleotides and vaccines, remains problematic to this day. Instability in the gastrointestinal environment and poor permeability across the intestinal epithelial cell barrier contribute to the poor oral bioavailability of many of these compounds [[99]]. Modulating the properties of vesicles by means of covalently or non-covalently attached or entrapped polymers [[100]] helps control their stability and permeability and imparts some specific surface properties [[95]]. S-layer proteins of some Bacillus and Lactobacillus species can be crystallized on liposomes composed of various phospholipids together with cholesterol, leading to a novel type of liposome (Table 3). Such S-layer coated liposomes are closed biomimetic structures that resemble archaeal cells, in which the S-layer proteins crystallize over the plasma membrane [[101]]. Natural association of S-layers with the cytoplasmic membrane occurs only in Archaea, where S-layers are anchored by hydrophobic stretches of protein 'stalks' that presumably act as immobilization structures for lipids and proteins, with unknown consequences for membrane properties in vivo [[13], [102]]. Interaction of S-layer proteins with lipid molecules is noncovalent. Electrostatic interaction between exposed carboxy groups on the inner face of the S-layer lattice and zwitterionic lipid head groups is primarily responsible for the binding and defined orientation of the S-layer subunits to form a closed lattice structure. It has been suggested that there are at least two to three contact points between the lipid film and the attached S-layer protein. Therefore, only a few lipid molecules would be anchored via their head groups to protein domains on the S-layer lattice; the remaining scores of lipid molecules diffuse freely in the membrane between the pillars consisting of anchored lipid molecules. Because of its fluid characteristic, this nanopatterned type of lipid membrane is also referred to as a 'semifluid membrane' [[103]]. However, most importantly, the attached Slayer lattices apparently have no effect on the hydrophobic lipid acyl chains. Thus, S-layer lattices constitute unique scaffolding for lipid membranes [[104]]. Use of these properties has potential for a broad spectrum of developments in many areas, including diagnostics, high-throughput screening for drug discovery, sensor technology, and electronic or optical devices; it might find application in DNA sequencing [[101]]. S-layer proteins, after they have been crystallized on liposomes, can be cross-linked and exploited as a matrix for the covalent attachment of functional molecules, which would be useful for drug targeting or immunodiagnostic assays [[106], [107]]. Although currently the most extensively studied S-layer proteins are those of Geobacillus stearothermophilus PV72/p2 and Bacillus sphaericus CCM 2177, many relevant nanobiotechnological applications can be expected from the utilization of S-layer proteins from other organisms, in particular Lactobacillus [[7]]. In recent studies with Slayer proteins of lactobacilli, we demonstrated the existence of protein-liposome interactions. Using electron micrographs, we showed that Slayer proteins are adsorbed on the liposome layer, covering the entire surface [[109]]. Furthermore, S-layer proteins isolated from GRAS lactobacilli are able to stabilize positively charged liposomes against different condition [45]. This effect could be explained by the concourse of different changes promoted by the proteins on the lipid bilayer. An increase in the bilayer packing due to charge neutralization decreases in the acyl chain mobility and hence permeability. In addition, S-layer proteins were 
able to decrease liposome fusion, probably to the inclusion of bulky moieties protruding from the membrane, giving place to steric hindrance for surface-surface interaction [[53]]. Studies on Caco-2 monolayers using liposomes coated with S-layer proteins from L. kefiri showed absence of cytotoxicity and also that coated liposomes were able to transfer more fluorescent molecules than control ones (without S-layers proteins) [[110]]. The natural adhesive properties of S-layer proteins to different epithelial cells probably promote the internalization, could explaining those results. The higher stability of S-layer-coated liposomes, combined with the adhesion and immunogenic functions of S-layer proteins, and the possibility for immobilizing or entrapping biologically active molecules [[106]] reveal a broad application potential, particularly as carrier and/or drug delivery [[103]]. S-layer lattices constitute unique supporting scaffoldings for lipid membranes that can be occupied by a great variety of membrane-active peptides and by peripheral and integral membrane proteins [[111]].

\section{Conclusions and perspectives}

S-layers have been identified in several Lactobacillus species. In some of these bacteria, S-layers have been shown to function as adhesins, mediating binding of lactobacilli to the host epithelial cells and/or ECM [[4]]. Due to these observed adhesive properties, including their high degree of structural regularity and their self-assembly properties, the possible therapeutic applications of lactobacillar S-layers have become increasingly of interest, e.g. as targeted antigen delivery vehicles to host tissues [[86], [111], [107]]. Slayers may provide superior expression levels and surface density of antigens when compared to other bacterial antigen presentation systems. It has already been demonstrated that S-layer protein subunits can be modified to carry foreign epitopes as a uniform recombinant S-layer on the lactobacilli cell surface [[92], [44]]. The application of the intrinsic adjuvanticity of lactobacilli as hosts, in constructing these vaccine strains, may result in the stimulation of immune responses to a coadministered antigen, surface-displayed as a part of the S-layer. Further advantages in employing lactobacilli as surface-display vectors include the health-promoting properties claimed for several strains [[112]], the GRAS status of lactobacilli [[113]] and the lack of LPS in the cell wall, which eliminates the risk of endotoxic shock [[84]]. However, there have been few immunization studies with Lactobacillus S-layer antigen constructs; favorable results from several immunization studies using recombinant S-layer proteins from other bacteria [[76], [88]] encouraged us to develop Lactobacillus S-layer based antigen carriers. The adhesion and immunogenic functions of S-layer proteins, combined with the properties of Lactobacillus spp., could lead to new, safe, and stable liposomal particles for drug delivery. The high mechanical and thermal stability of S-layer-coated liposomes and the possibility for immobilizing or entrapping biologically active molecules [[114]] are important properties for liposome processing, as the vesicles have to resist processing manipulations, including stirring, pumping and resuspension, and they need to pass across the gastrointestinal tract. For medical applications, increased stability of liposomal preparations is essential for formulations that must be administered orally, because the liposomes will be exposed to a harsh environment [[109]]. Another potential application for lactobacillar S-layers is in nanotechnology, in which self-assembly systems are exploited for the activation of surfaces as well as for the production of biomimetic membranes and encapsulation systems [[7]].

\section{ACKNOWLEDGEMENTS}

This work was supported by grants from Universidad Nacional Quilmes, CAPES-SECyT 012-2006, Comisión de Investigaciones Científicas de la Provincia de Buenos Aires (CIC-BA), Fundação de Amparo à Pesquisa do Estado de Minas Gerais (FAPEMIG Brazil), and Conselho Nacional de Pesquisa (CNPq - Brazil). Dr. L. Semorile and Dr. G. De Antoni are members of the Research Career of CIC-BA. Dr. E. A. Disalvo is member of the Research Career of CONICET.

\section{REFERENCES}

[1] Bernardeau M., Vernoux J.P., HenriDubernet S. and Guéguen M. (2008) Int J Food Microbiol., 126(3), 278-285.

[2] Felis G.E. and Dellaglio F. (2007) Curr. Issues Intestinal Microbiol., 8 , 44-61.

[3] Björkroth J., Ristiniemi M., Vandamme P.and Korkeala H. (2005) Int. J. Food Microbiol., 97, 267-276.

[4] Åvall-Jääskeläinen S. and Palva A. (2005) FEMS Microbiol. Rev., 29, 511-529.

[5] Sleytr U.B. (1978). Int. Rev. Cytol., 53, 1-64.

[6] Sleytr U.B. and Glauert A.M. (1975) J. Ultrastruct. Res., 50, 103-116.

[7] Sleytr U.B., Huber C., Ilk N., Pum D., Schuster B. and Egelseer E.M. (2007) FEMS Microbiol. Lett., 267, 131-144.

[8] Masuda K. and Kawata T. (1979) Microbiol. Immunol., 23, 941-953.

[9] Fouet A. (2009). Mol Aspects Med. 30(6), 374-385

[10] Engelhardt H. (2007) J. Struct. Biol., 160, 115-124.

[11] Lepault J., Martin M. and Leonard K. (1986) J. Bacteriol., 168, 303-308.

[12] Sàra M. and Sleytr U.B. (2000) J. Bacteriol., 182, 859-868. 
[13] Baumeister W. and Lembcke G (1992) J Bioenerg. Biomembr., 24, 567-575.

[14] Sleytr U.B., Sàra M., Pum D. and Schuster B. (2001) Prog. Surf. Sci., 68, 231-278.

[15] Sleytr U.B. and Beveridge T.J. (1999) Trends Microbiol., 7, 253-260.

[16] Schuster B. and Sleytr U. B. (2000) Rev. Mol. Biotechnol., 74, 233-254.

[17] Jakava-Viljanen M., AvallJaaskelainen S., Messner P., Sleytr U.B. and Palva A. (2002) J. Bacteriol., 184, 6786-6795.

[18] Etienne-Toumelin I., Sirard J.C., Duflot E., Mock M. and Fouet A. (1995) J. Bacteriol., 177, 614-620.

[19] Mesnage S., Tosi-Couture E., Mock M., Gounon P.and Fouet A. (1997) Mol. Microbiol., 23, 1147-1155.

[20] Takeoka A., Takumi K., Koga T. and Kawata T. (1991) J. Gen. Microbiol., 137, 261-267.

[21] Verbelen C., Antikainen J., Korhonen T.K. and Dufrene Y.F. (2007) Ultramicroscopy, 107, 1004-1011.

[22] Garrote G.L., Delfederico L., Bibiloni R., Abraham A. G., Pérez P.F., Semorile L., De Antoni G.L. (2004) J. Dairy Res., 71, 222-230.

[23] Sumper M. and Wieland F.T. (1995) In: Glycoproteins (Eds. J. Montreuil, J.F.G. Vliegenthart and H. Schachter). Amsterdam: Elsevier, 455-473.

[24] Sleytr U.B., Schuster B. and Pum D. (2003) IEEE. Eng. Med. Biol. Mag., 22, 140-150.

[25] Schäffer C. and Messner P. (2004) Glycobiology, 14, 31-42.

[26] Messner P., Steiner K., Zarschler K. Schäffer C. (2008) Carbohydr. Res., 343, 1934-1951.

[27] Engelhardt H. and J. Peters. (1998) J. Struct. Biol., 124, 276-302.

[28] Steiner K., Hanreich A., Kainz B. Hitchen P. G., Dell A., Messner P. and Schäffer C. (2008) Small, 4, 17281740

[29] Steiner K., Novotny R., Werz D. B., Zarschler K., Seeberger P. H., Hofinger A., Kosma P., Schäffer C. and Messner P. (2008) J. Biol. Chem., 283, 21120-21133.

[30] Zarschler K., Janesch B., Zayni S., Schäffer C. and Messner P. (2009) Appl. Environ. Microbiol., 75, 30773085.

[31] Lupas A., Engelhardt H., Peters J., Santarius U., Volker S. and Baumeister W. (1994) J. Bacteriol., 176, 1224-1233.

[32] Leibovitz E., Ohayon H., Gounon P and Béquin P. (1997) J. Bacteriol., 179, 2519-2523.

[33] Olabarría G., Carrascosa J.L., de Pedro M.A. and Berenguer J. (1996) J. Bacteriol., 178, 4765-4772.
[34] Zhao G, Li H., Wamalwa B., Sakka M. Kimura T., Sakka K. (2006) Biosci. Biotechnol. Biochem., 70, 1636-1641.

[35] Antikainen J. (2007) Ph.D. thesis. University of Helsinki, Finland.

[36] Boot H.J., Kolen C.P.A.M., van Noort J.M. and Pouwels P.H. (1995) J. Bacteriol., 177, 7222-7230.

[37] Sillanpää J., Martínez B., Antikainen J., Toba T., Kalkinnen N., Tankka S., Luonatmaa K., Keränen J., Höök M., Westerlund-Wikström B., Powels P.H. and Korhonen T.K. (2000) J. Bacteriol., 182, 6440-6450.

[38] Fouet A. and Mesnage S. (2002) Curr. Top. Microbiol. Immunol., 271, 87113.

[39] Grogono-Thomas, R., Dworkin J., Blaser M.J. and Newell D.G. (2003) Infect. Immunol., 68, 1687-1691.

[40] Lee S.W., Sabet M., Um H.S., Yang J., Kim H.C. and Zhu W. (2006) Gene, 371, 102-111.

[41] Masuda K. and Kawata T. (1981) J. Gen. Microbiol., 124, 81-90.

[42] Masuda K. and Kawata T. (1983) FEMS Microbiol. Lett., 20, 145-150.

[43] Avall-Jääskeläinen S, Hynönen U., Ilk N., Pum D., Sleytr U.B. and Palva A. (2008) BMC Microbiol., 8,165.

[44] Smit E., Jager D., Martinez B., Tielen F. J. and Pouwels P.H. (2002) J. Mol. Biol., 324, 953-964.

[45] Antikainen J., Anton L., Sillanpää J. and Korhonen T. K. (2002). Mol. Microbiol., 46, 381-394.

[46] Moschl A., S. Schaffer, U.B. Sleytr and P. Messner. (1993) In: Bacterial Paracrystaline Surface Arrays, (Eds. T.J. Beveridge and S.F. Kowal ). New York:Plenum Press, 281-284.

[47] Delfederico L. (2007) Ph. D. thesis. University of Quilmes, Argentine.

[48] Mobili P., Serradell M., Trejo S.A., Avilés Puigvert F.X., Abraham A.G. and De Antoni G.L. (2009) Antonie Van Leeuwenhoek, 95, 363-372.

[49] Mozes N. and Lortal S. (1995) Microbiology, 141, 11-19,

[50] Mercenier A., Pavan S. and Pot B. (2003) Curr. Pharm. Des., 9, 175-191.

[51] Ristl, R., Steiner K., Zarschler K., Zayni S., Messner P. and Schäffer C. (2011) Int. J. Microbiol., 2011, Article ID 127870.

[52] Messner P., Allmaier G., Schäffer C., Wugeditsch T., Lortal S., König H., Niemetz R. and Dorner M. (1997) FEMS Microbiol. Rev., 20, 25-46.

[53] Hollmann A., Delfederico L., De Antoni G., Semorile L. and Disalvo E.A. (2010) Colloids Surf. B Biointerfaces, 79, $191-197$.

[54] Frece J., Kos B., Svetec I.K., Zgaga Z., Mrsa V. and Susković J. (2005) J. Appl. Microbiol., 98, 285-292. 
[55] Schneitz C., Nuotro N.and Kounatma K. (1993) J. Appl. Bacteriol., 74, 290294.

[56] Hynönen U., Westerlund B., Palva A.and Korhonen T.K. (2002) J. Bacteriol., 184, 3360-3367.

[57] Toba T., Virkola R., Westerlund B., Bjorkman Y., Sillampää J., Vartio T., Kalkkinen N. and Korhonen T.K. (1995) Appl. Environ. Microbiol., 61, 2467-2471.

[58] Jakava-Viljanen $M$. and Palva A. (2007) Vet. Microbiol., 124, 264-273.

[59] Ouwehand A.C., Kirjavainen P.V., Groönlund N.M., Isolauri E. and Salminen S.J. (1999) Int. Dairy J., 9, 623-630.

[60] Servin A.L. and Coconnier M.H. (2003) Baillieres Best Pract. Res. Clin. Gastroenterol., 17, 741-754.

[61] Cesena C., Morelli L., Alander M., Siljander T., Tuomola E., Salminen S., Mattila-Sandholm T. and Von Wright A. (2001) J. Dairy Sci., 84, 10011010.

[62] Pérez P.F., Minnaard Y., Disalvo E.A and De Antoni G.L. (1998) Appl. Environ. Microbiol., 64, 21-26.

[63] de Leeuw E., Li X. and Lu W. (2006) FEMS Microbiol. Lett., 260, 210-215.

[64] Golowczyc M.A., Mobili P., Garrote G.L., Abraham A.G. and De Antoni G.L. (2007) Int. J. Food Microbiol., 118, 264-273.

[65] Golowczyc M.A., Mobili P., Garrote G.L., de Los Angeles Serradell M, Abraham A.G., De Antoni G.L. (2009) J. Dairy Res., 76, 111-116.

[66] Chen X., Xu J., Shuai J., Chen J., Zhang Z. and Fang W. (2007) Int. J. Food Microbiol., 115, 307-312.

[67] Johnson-Henry, K.C., Hagen K.E. Gordonpour M., Tompkins T.A. and Sherman P.M. (2007) Cell Microbiol., 9, 356-367.

[68] Zhang Y.C., Zhang L.W., Tuo Y.F., Guo C.F., Yi H.X., Li J.Y., Han X. and Du M. (2010) Res. Microbiol., In press

[69] Prado Acosta M. Palomino M.M. Allievi M.C., Sanchez Rivas C. and Ruzal S.M. (2008) Appl. Environ. Microbiol., 74, 7824-7827.

[70] Prado Acosta M, Ruzal S.M., Allievi M.C., Palomino M.M. and Sanchez Rivas C. (2010) Appl. Environ. Microbiol., 76, 974-977.

[71] Buck B.L., Altermann E., Svingerud T. and Klaenhammer T.R. (2005) Appl. Environ. Microbiol., 71, 8344-8351.

[72] Sára M., D. Pum, C. Huber, N. Ilk, M Pleschberger and U.B. Sleytr (2006) In: Biological and Pharmaceutical Nanomaterials. Nanotechnologies for the Life Sciences, Vol. 2, (Eds. C. Kumar). Weinheim, Germany:Wiley$\mathrm{VCH}, 219-252$.
[73] Smith R.H., Messner P., Lamontagne L.R., Sleytr U.B. and Unger F. M. (1993) Vaccine, 11, 919-924.

[74] Messner P., Christian R., Kolbe J., Schulz G. and Sleytr U.B. (1992) J. Bacteriol., 174, 2236-2240.

[75] Jahn-Schmid B., Messner P., Unger F.M., Sleytr U.B., Scheiner O. and Kraft D. (1996) J. Biotechnol., 44, 225231.

[76] Riedmann E.M., Kyd J.M., Smith A.M., Gomez-Gallego S., Jalava K., Cripps A.W. and Lubitz W. (2003) FEMS Immunol. Med. Microbiol., 37, 185192.

[77] Lubitz, W. (2001) Expert Opin. Biol. Ther., 1, 765-771.

[78] Wang L., Sun M. and Yu. Z. (2004) Appl. Biochem. Biotechnol., 119, 133143.

[79] Liu M Li S., Hu S., Zhao C., Bi D. and Sun M. (2008) Appl. Microbiol. Biotechnol., 78, 669-676.

[80] Khang Y.H., Park H.Y., Jeong Y.S. Kim J.A. and Kim Y.H. (2009) J. Microbiol. Biotechnol., 19, 511-519.

[81] Konstantinov S.R., Smidt H., de Vos W.M., Bruijns S.C., Singh S.K., Valence F., Molle D., Lortal S., Altermann E., Klaenhammer T.R. and van Kooyk Y. (2008) Proc. Natl. Acad. Sci. U S A, 105, 19474-19479.

[82] Geoffroy M.C., Guyard C. Quatannens B., Pavan S., Lange M. and Mercenier A. (2000) Appl. Environ. Microbiol., 66, 383-391.

[83] Kullen M.J. and Klaenhammer T.R (2000) Curr. Issues Mol. Biol., 2, 4150.

[84] Mercenier, A., Müller-Alouf H. and Grangette C. (2000) Curr. Issues Mol. Biol., 2, 17-25.

[85] Norton P.M., Le Page R.W., Wells J.M. (1995) Folia Microbiol (Praha), 40, 225-230.

[86] Reveneau N., Geoffroy M.C., Locht C., Chagnaud P. and Mercenier A. (2002) Vaccine, 20, 1769-1777.

[87] Havenith C.E.G., Seegers, J.F.M.L. and Pouwels P.H. (2002) Food Res. Intern., 35, 151-163.

[88] Umelo-Njaka E., Nomellini J. F., Bingle W. H., Glasier L. G., Irvin R. T. and Smit J. (2001) Vaccine, 19, 14061415.

[89] Sleytr U.B. and Messner P. (1983) Ann. Rev. Microbiol., 37, 311-339.

[90] Hynönen U., Avall-Jääskeläinen S. Palva A. (2010) Appl. Microbiol. Biotechnol., 87, 657-668

[91] Khaleghi M., Kermanshahi R.K., Yaghoobi M.M., Zarkesh-Esfahani S.H. and Baghizadeh A. (2010) J. Microbiol. Biotechnol., 20, 749-756.

[92] Avall-Jääskeläinen S., Kylä-Nikkilä K., Kahala M., Miikkulainen-Lahti T. and 
Palva A. (2002) Appl. Environ Microbiol., 68, 5943-5951.

[93] Chen X., Chen Y., Li X., Chen N., Fang W. (2009) J. Microbiol. Biotechnol., 19, 1176-1183.

[94] Lasic D.D. (1998) Trends Biotechnol., 16, 307-321.

[95] Volodkin D., Mohwald H., Voegel J.C and Ball V. (2007) J. Control Release, 117, 111-120.

[96] Gombotz W.R. and Wee S. (1998) Adv. Drug Deliv. Rev., 31, 267-285.

[97] Rebelatto M.C., Guimond P., Bowersock T.L., HogenEsch H. (2001) Vet. Immunol. Immunopathol., 83, 93105.

[98] Alpar H.O., Bowen J.C., Brown M.R.W. (1992) Int. J. Pharm., 88, 335-344.

[99] Alonso-Romanowski S., Chiaramoni N.S. Lioy V.S, Gargini R.A. Viera L.I. and Taira M.C. (2003) Chem. Phys. Lipids, 122, 191-203.

[100] Ishihara K., Tsujino R., Hamada M. Toyoda N., Iwasaki Y. (2002) Colloids Surf., B Biointerfaces, 25, 325-333.

[101] Kostarelos K., Emfietzoglouc D.and Tadros T.F. (2005) Faraday Discuss., 128, 379-388.

[102] Schuster B. and Sleytr U.B. (2006) Curr. Nanosci., 2, 143-152.

[103] Baumeister W., Wildhaber I. and Phipps B. M. (1989) Can. J. Microbiol., 35, 215-222

[104] Pum D. and Sleytr U.B. (1994) Thin Solid Films, 244, 882-886.

[105] Schuster B. (2005) Nanobiotechnology, 1, 153-164.

[106] Illk N., Küpcü S., Moncayo G., Klimt S., Ecker R.C., Hofer-Warbinek R., Egelseer E.M., Sleytr U.B. and Sara M. (2004) Biochem. J., 379, 441-448.

[107] Shaw D.M., Gaerthé B., Leer R.J., van der Stap J.G.M.M., Smittenaar C., Heijne

[108] den Bak-Glashouwer M.J., Thole J.E.R., Tielen F.J., Pouwels P.H. and Havenith C.E.G. (2000) Immunology, $100,510-518$.

[109] Hollmann A., Delfederico L., Glikmann G., De Antoni G.L., Semorile L. and Disalvo E.A. (2007) Biochim. Biophys. Acta, 1768, 393-400.

[110] Hollmann A. (2009) Ph. D. thesis. University of Quilmes, Argentine.

[111] Schuster B., Gufler P.C., Pum D. and Sleytr U.B. (2004) IEEE Trans. Nanobioscience, 3, 16-21.
[112] Scheppler, L., Vogel M., Zuercher M. Germond J.E., Miescher S.M. and Stadler B.M. (2002) Vaccine, 20, 2913-2920.

[113] Adams M.R. and Marteau P. (1995) Int. J. Food Microbiol., 27, 263-264.

[114] Mader C., Küpcü S., Sleytr U.B. and Sára M. (2000) Biochim. Biophys. Acta, 1463, 142-150.

[115] Felis G.E. and Dellaglio F. (2007) Curr. Issues. Intest. Microbiol., 8(2), 44-61.

[116] Masuda K. (1992). Microbiol. Immunol., 36, 297-301.

[117] Boot H.J., Kolen C.P.A.M., van Noort J.M. and Pouwels P.H. (1993) J. Bacteriol., 175, 6089-6096.

[118] Boot H.J., Kolen C.P.A.M, van Noort J.M. and Pouwels P.H. (1996) Microbiology, 142, 2375-2384

[119] Vidgrén G., Palva I., Pakkanen R., Lounatmaa K. and Palva A. (1992) J. Bacteriol., 62, 513-520

[120] Barker D.C. and Thorne K.J.I. (1970). J. Cell Sci., 7, 755-785.

[121] Hagen K., Guan L., Tannock G.W. Korver D.R. and Allison G.E. (2005) Appl. Environ. Microbiol., 71, 66336643.

[122] Ventura M., Jankovic I., Walker D.C., Pridmore R.D. and Zink R. (2002) Appl. Environ. Microbiol., 68, 61726181

[123] Callegari M.L., Riboli B., Sanders J.W., Cocconcelli P.S., Kok J., Venema G. and Morelli L. (1998) Microbiology, 144, 719-726.

[124] Lortal S., van Heijenoort J., Gruber K. and Sleytr U.B. (1992) J. Gen. Microbiol., 138, 611-638

[125] Mader C., Küpcü S., Sara M. and Slyter U.B. (1999) Biochim. Biophys. Acta, 1418, 106-116.

[126] Küpcü S., Lohner K., Mader C. and Sleytr U.B. (1998) Mol. Membr. Biol., 2, 69-74.

[127] Küpcü S., Sára M. and Sleytr U.B. (1995) Biochim. Biophys. Acta, 1235, 263-269.

[128] Weygand M., Wetzer B., Pum D., Sleytr U.B., Cuvillier N., Kjaer K., Howes P.B. and Lösche M. (1999) Biophys. J., 76, 458-468.

[129] Diederich A., Sponer C., Pum D. Sleytr U.B. and Lösche M. (1996) Colloids Surf. B.: Biomembranes, 6, 335-346. 


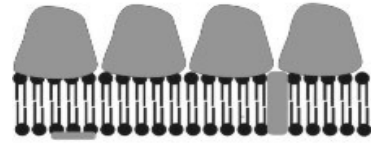

A

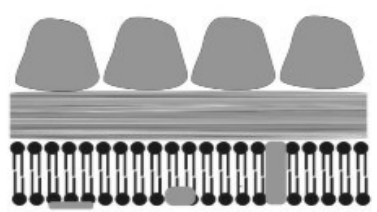

B

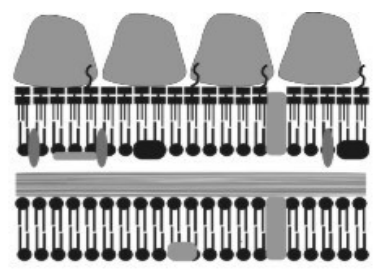

C

\section{S-layer protein $\$$ membrane protein \\ l. membrane lipid petidoglycan}

Fig. 1- Schematic illustration of the cell-envelope structure of archaeas (A), Gram-positive (B) and Gram-negative bacteria $(C)$ with S-layer. Modified from Schuster et al. [[16]].
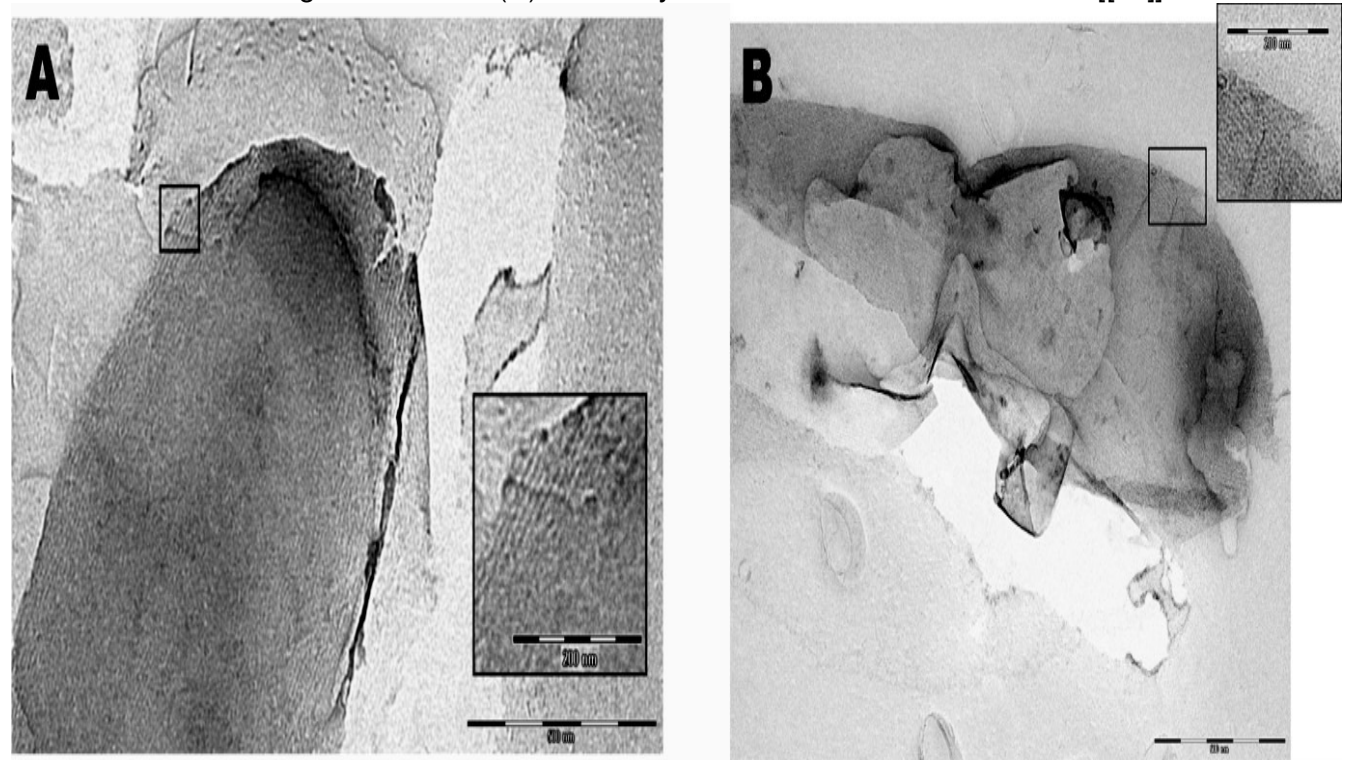

Fig. 2- Transmission electron micrographs of freeze drying entire cell of $L$. kefiri $(A)$ and $L$. buchneri $(B)$. Barrs. 500 nm., Zoom in $200 \mathrm{~nm}$.
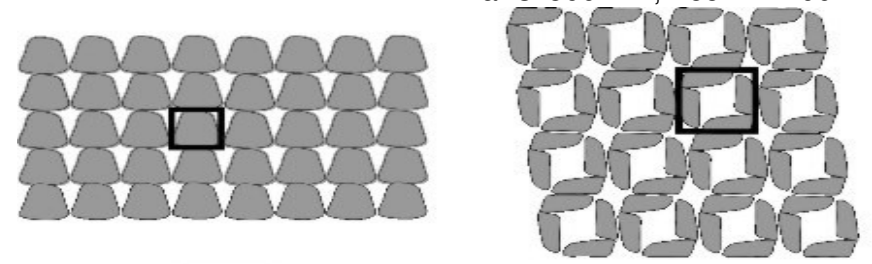

p1

p2

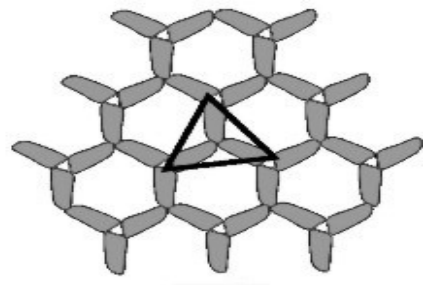

p3

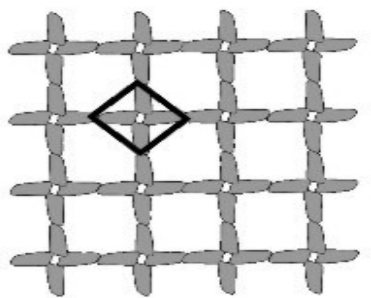

p4



p6

Fig. 3- Schematic drawings of the different S-layer lattice types. The regular arrays either show oblique $(p 1, p 2)$, square (p4) or hexagonal $(p 3, p 6)$ lattice symmetry. Modified from Sleytr et al. [[14]]. 




Fig. 4- Neighbor-Joining tree based on 16S rRNA gene sequences of Lactobacillus species defined by Fellis and Dellaglio, [115]. In bold underlined are indicated phylogenetic groups were S-layer carrying species have been reported.

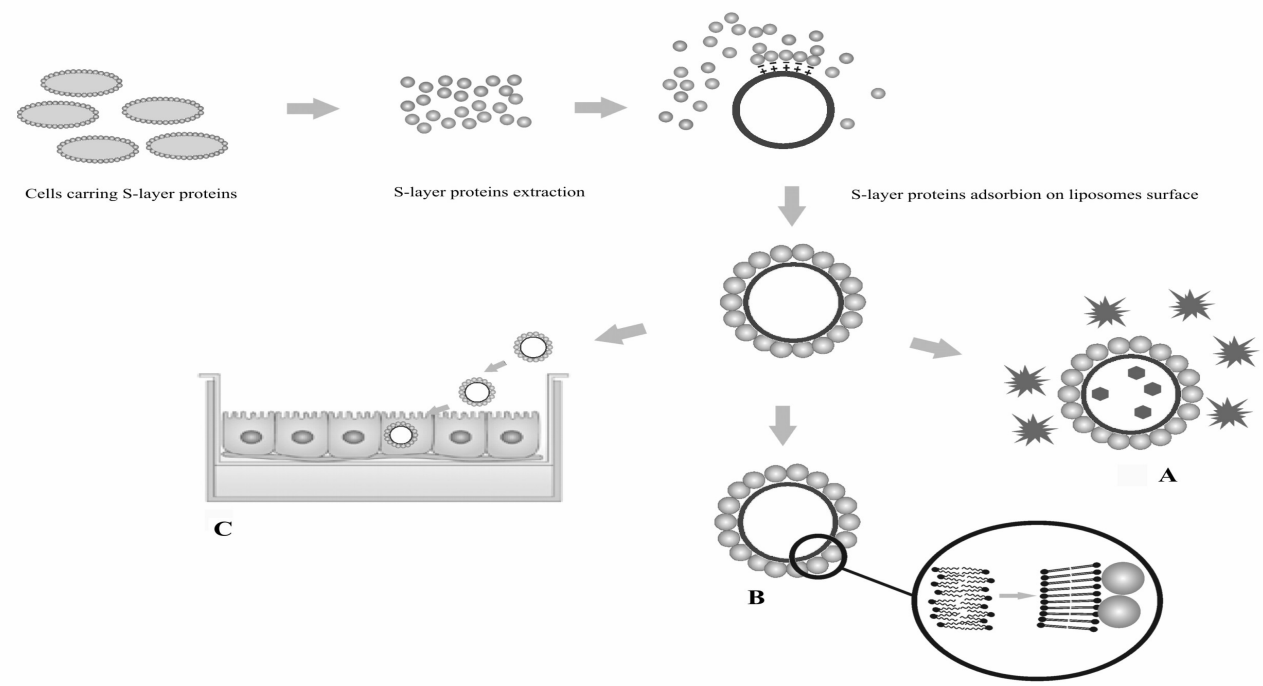

Fig. 5- Schematic representation of the S-layer protein obtention and adsorption to the external surface of liposomes and its effects against stress factors (A), on the lipid properties (B) and on their internalization rate on Caco-2 cells monolayers (C). 
Table 1- Lactobacillus species that possess an S-layer

\begin{tabular}{|c|c|c|c|}
\hline Species & Strain & Genes & Reference \\
\hline Lactobacillus acidophilus & $\begin{array}{l}\text { ATCC } 4355 \\
\text { ATCC } 4356\end{array}$ & $s / p A, s / p B$ & $\begin{array}{l}{[116]} \\
{[117,36]}\end{array}$ \\
\hline Lactobacillus amylovorus & $\begin{array}{l}\text { LMG } 9496 \\
7 \text { isolates }\end{array}$ & - & $\begin{array}{l}{[118]} \\
{[58]}\end{array}$ \\
\hline Lactobacillus brevis & $\begin{array}{l}\text { ATCC } 8287 \\
\text { ATCC } 14869\end{array}$ & $\begin{array}{l}s / p A \\
s / p B, s / p C, s / p D\end{array}$ & $\begin{array}{l}119] \\
{[17]}\end{array}$ \\
\hline Lactobacillus buchneri & ATCC 4005 & - & [8] \\
\hline Lactobacullus casei & ATCC 7469 & - & [120] \\
\hline Lactobacillus crispatus & JCM 5810 & $c b s A, c b s B$ & {$[57]$} \\
\hline Lactobacillus fermentum & $\begin{array}{l}\text { NCTC } 7230 \\
\text { NCIB } 6991\end{array}$ & - & [42] \\
\hline Lactobacillus gallinarum & $\begin{array}{l}\text { ATCC } 33199 \\
8 \text { strains }\end{array}$ & $\begin{array}{l}\lg s, \text {, IgsI } \\
\lg s A, \lg s C, \lg s D, \lg s E, \operatorname{lgs} F, \\
\lg s G, \lg s H\end{array}$ & $\begin{array}{l}{[118]} \\
{[121]}\end{array}$ \\
\hline Lactobacillus gasseri, & ATCC 19992 & apf1, apf2 & [122] \\
\hline Lactobacillus johnsonii & 5 strains & - & [122] \\
\hline Lactobacillus helveticus & $\begin{array}{l}\text { ATCC } 12046 \\
\text { CNRZ } 892 \text { (ATCC } \\
10386)\end{array}$ & slpH1, s/pH2 & {$[123,124]$} \\
\hline Lactobacillus kefiri & $\begin{array}{l}20 \text { isolates, JCM } \\
5818, \text { ATCC } 8007\end{array}$ & - & [22] \\
\hline Lactobacillus parakefiri & & - & {$[22]$} \\
\hline
\end{tabular}


Table 2- Proposed or identified adhesive surface proteins of Lactobacillus

\begin{tabular}{|l|l|l|c|}
\hline S-layer protein & Target & Species / Strain & Reference \\
\hline S-layer protein & Avian intestinal epithelial cells & Lactobacillus acidophilus spp. & {$[55]$} \\
\hline CbSA & Collagens, laminin & Lactobacillus crispatus JCM5810 & {$[57]$} \\
\hline SlpA & $\begin{array}{l}\text { Fibronectin, human epithelial } \\
\text { cell line }\end{array}$ & Lactobacillus brevis ATCC8287 & {$[56]$} \\
\hline S-layer protein & Red blood cells & Lactobacillus kefiri CIDCA8321 & {$[22]$} \\
\hline & & Lactobacillus parakefiri CIDCA8328 & {$[54]$} \\
\hline SlpA & Murine ileal epithelial cells & Lactobacillus acidophilus M92 & {$[53]$} \\
\hline S-layer protein & human epithelial cells & Lactobacillus helveticus R0052 & {$[58]$} \\
\hline S-layer protein & Mammalian epithelial cell & Lactobacillus amylovorus spp. & {$[65]$} \\
\hline S-layer protein & Sacch. lipolytica & Lactobacillus kefiri CIDCA 8315 & \\
\hline
\end{tabular}

Table 3- Evidence of S-layer proteins able to recrystallice on lipid interfaces

\begin{tabular}{|l|c|c|}
\hline Organism & Lipid interface & Reference \\
\hline Lactobacillus brevis & liposomes & {$[53,109]$} \\
\hline Lactobacillus kefiri & liposomes & {$[53,109]$} \\
\hline Bacillus sphaericus & lipid monolayer & {$[128,129]$} \\
\hline Geobacillus stearothemophilus & liposomes & {$[127]$} \\
\hline Bacillus coagulans & liposomes & {$[125]$} \\
\hline
\end{tabular}

Table 4-Characteristics of liposomes coated with S-layer proteins.

\begin{tabular}{|l|l|c|}
\hline \multicolumn{2}{|l|}{ Effect on liposome } & Reference \\
\hline Stabilization effects against & Bile salt & {$[109]$} \\
\hline & Pancreatic extracts & {$[109]$} \\
\hline & Lower pH & {$[109]$} \\
\hline & Mechanical stress & {$[125]$} \\
\hline Inversion of the $\xi$-potential in positively charged liposomes & {$[109,125]$} \\
\hline Stabilization of the liquid-ordered gel-like state & Temperature stress & {$[126]$} \\
\hline Ordering of the lipid molecules & {$[53]$} \\
\hline Inhibition of spontaneous fusion & {$[53]$} \\
\hline
\end{tabular}

